Papers and Proceedings of the Royal Society of Tasmania, Vo1.109, 1975.

(ms. received 11.7 .1974$)$

\title{
PLANT SPECIES DIVERSITY OF THE LAKE DORA ISLANDS, TASMANIA
}

\author{
by J.B. Kirkpatrick
}

Geography Department, University of Tasmania

(with three text-figures and one plate)

\section{ABSTRACT}

The relationship between the areas and plant species number of sixteen small islands in a Tasmanian subalpine lake is described. The nature of the island area species diversity curve seems to be strongly affected by island area rather than habitat heterogeneity, and by differences in species diversity in the vegetation zones found on the island.

\section{INTRODUCTION}

Lake Dora is one of the largest of many lakes which fill the basins in a glacially eroded 'knock and lochan' 1 andscape in a part of north-western Tasmania receiving more than $3000 \mathrm{~mm}$ of precipitation per annum. The lake is $750 \mathrm{~m}$ above sea level and contains sixteen small islands (fig. 1) which vary in size from five sq. m to $375 \mathrm{sq}$. m. Some of these islands are apparently roches moutonnees, but most are Cambrian volcanic rock outcrops of slightly higher altitude than the lake surface.

The islands have biogeographic interest in that: they vary markedly in size while being all very small; their vegetation has developed under almost identical edaphic and climatic conditions; and the hinterland of the lake is covered by a vegetation which differs markedly in both floristics and structure from that of the islands. Thus, they offer the opportunity to provide substantive data relevant to theories of island biogeography from a relatively unusual situation.

\section{METHODS}

Species lists were made of al1 Pteridophyta, Gymnospermae and Angiospermae found on each island in 1ate January 1973. Nomenclature in this paper follows Curtis (1956, 1963 and 1967) for the Gymnospermae and Dicotyledoneae, and Wil1is (1970) for the Pteridophyta and Monocotyledoneae excepting the Tasmanian endemics for which authorities are given (Appendix). The areas of the islands were measured from large scale aerial photographs.

\section{RESULTS AND DISCUSSION}

Fifty-five species were found on the islands of which 28 were Tasmanian endemics (Appendix). The number of species on individual islands varied from 12 to 32 .

The number of species per island increases linearly to an island size of $36 \mathrm{sq}$. $m$ (fig. 2). The correlation coefficient for the relationship between species number and island area including only islands to this size is $0.9069(0.001<\mathrm{p}<0.002)$. The larger islands exhibit virtually no increase in species diversity with increasing area (fig. 2), this being reflected in the fact that forty-seven of the fifty-five species recorded for the islands are found on at least one of the islands $36 \mathrm{sq}$. m and under in area (fig. 3).

The sharp increase in species number with area on the smaller islands is partially 


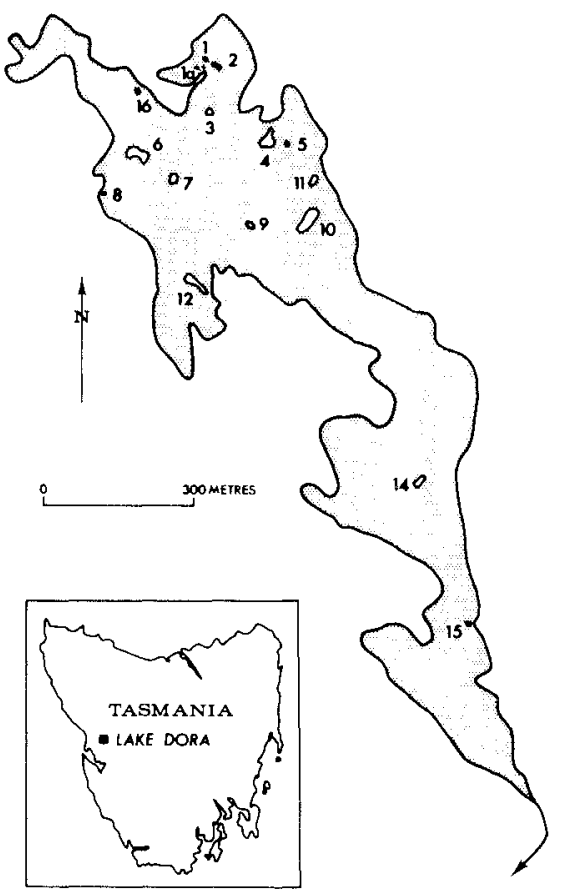

due to the islands being so small that they do not attain the minimal area for the island vegetation type. The lack of space for growth on these islands 1 imits the number of plants that can co-exist and this in turn limits the number of species. This is particularly important as many of the 55 species found on the islands are shrubs attaining diameters of over one metre and heights of over two metres.

As could be expected following from this argument, the correlation between island species number and island area up to $36 \mathrm{sq} . \mathrm{m}$ is improved by excluding herbs $(r=0.9146,0.001<p<0.002)$, and even the disparities in species number between the larger islands are reduced (fig. 2). Thus, the rapid increase in species number with increase in island size up to $36 \mathrm{sq} . \mathrm{m}$ is partly area controlled, rather than being controlled entirely by habitat heterogeneity.

The flattening of the species diversity/ area curve past $36 \mathrm{sq}$. $m$ is a product of the nature of the response of the island vegetation to increased habitat heterogeneity. Three vegetation zones can be distinguished on the islands, only one of which is fully developed on all. Below the extreme high water mark are found three species; Restio tetraphyzzus which forms a fringing rhizome

FIG. 1. - Location and coding of islands. mat, Baeckea gunniana which grows among the rushes in shallower water, and the endemic

gymnosperm Disetma archeri which is found close to the high water mark. The second zone consists of a $2-4 \mathrm{~m}$ high dense and tangled growth of shrub species, with an occasional emergent $5-7 \mathrm{~m}$ tall tree of ice-abraded Athrotaxis cupressoides (p1ate 1). This second zone is well developed on all but the two smallest islands, although the species richness of the zone increases to an island size of $36 \mathrm{sq}$. m. The presence of the third zone on an island depends on the island being large enough to have habitats protected from the effects of strong ice-laden winds. This zone consists of the climax vegetation for the altitude and rainfall of the islands. This vegetation is not as species rich as the vegetation of the second zone, and many of the species found in the second zone are also found in the third. Only five species are confined to the third zone on the islands, and only three of these species are found on more than one island. Almost al1 the species found in the climax forest at similar altitudes in non-1acustrine areas are found on the islands. Thus, any further increase in island size would almost certainly not involve a marked increase in species number.

One of the more interesting features of the floristic composiiion of the island vegetation is the presence of a number of species which are not usually found in areas undisturbed by fire. These species are abundant in the scrubs, sedgelands and moorlands which are produced by a history of relatively frequent firing (Jackson 1968). Most of the plateau on which Lake Dora is situated is covered by scrub, sedgeland and moorland, with some areas of rainforest in early stages of succession in situations normally sheltered from fires, and with eucalypt dominated communites found in we11drained rocky areas. The islands appear to have escaped the deflecting influence of fire, along with a small section of the southeast shoreline of the lake which is 
J.B. Kirkpatrick
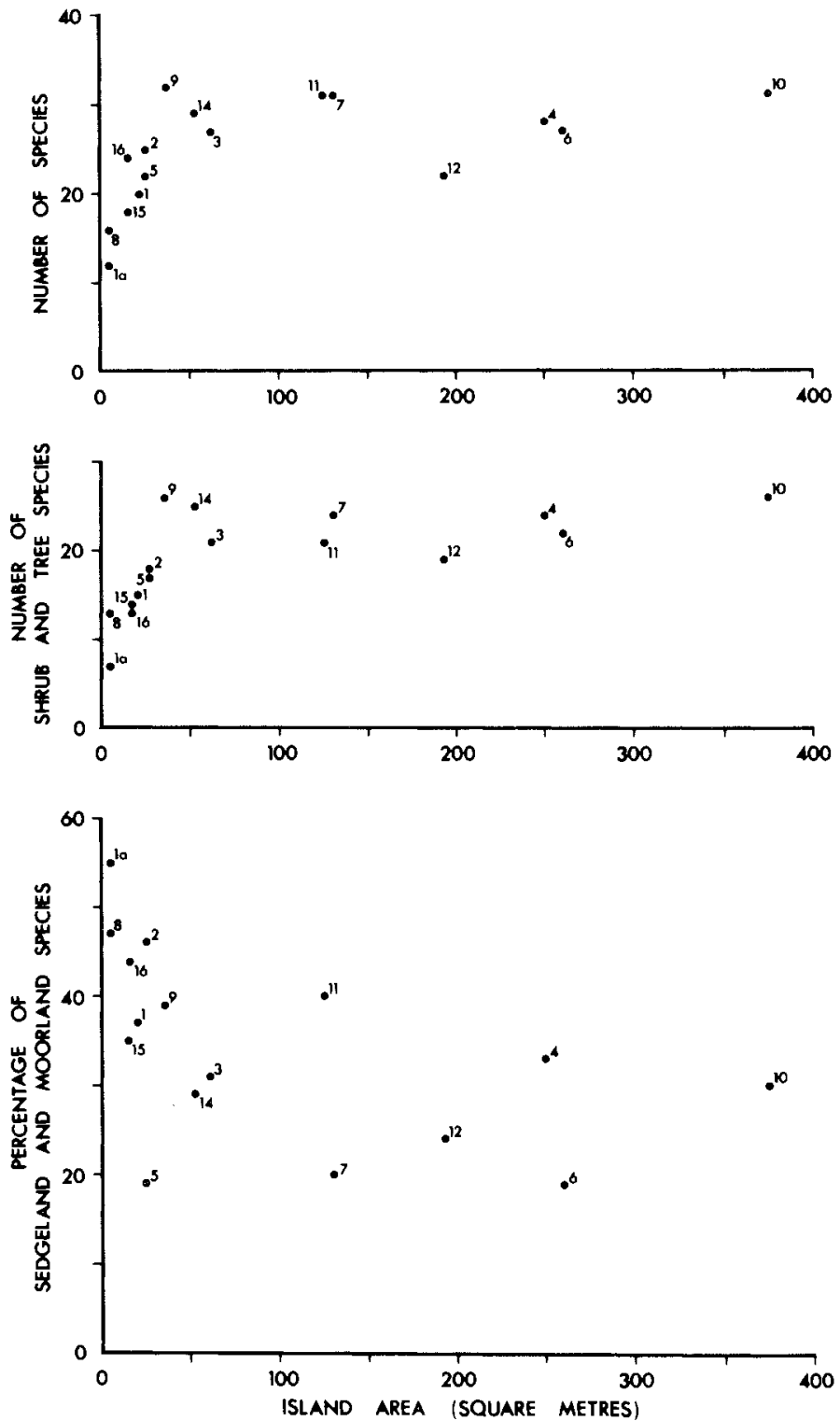

FIG. 2. - The relationship between species number and is land area (top); the relationship between shrub and tree species number and island area (middle); the relationship between the number of species usually confined to fire disclimax communities and island area (bottom). 


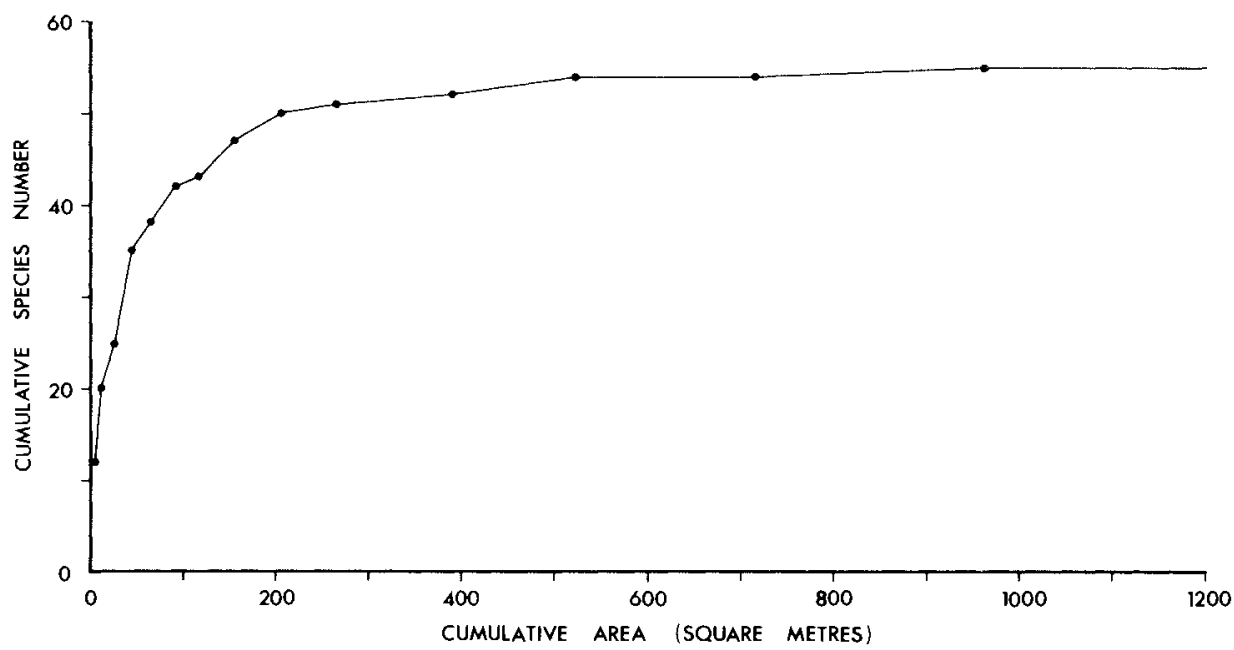

FIG. 3. - The cumulative species/area curve for the Lake Dora islands. No extra species were found on the largest two islands.

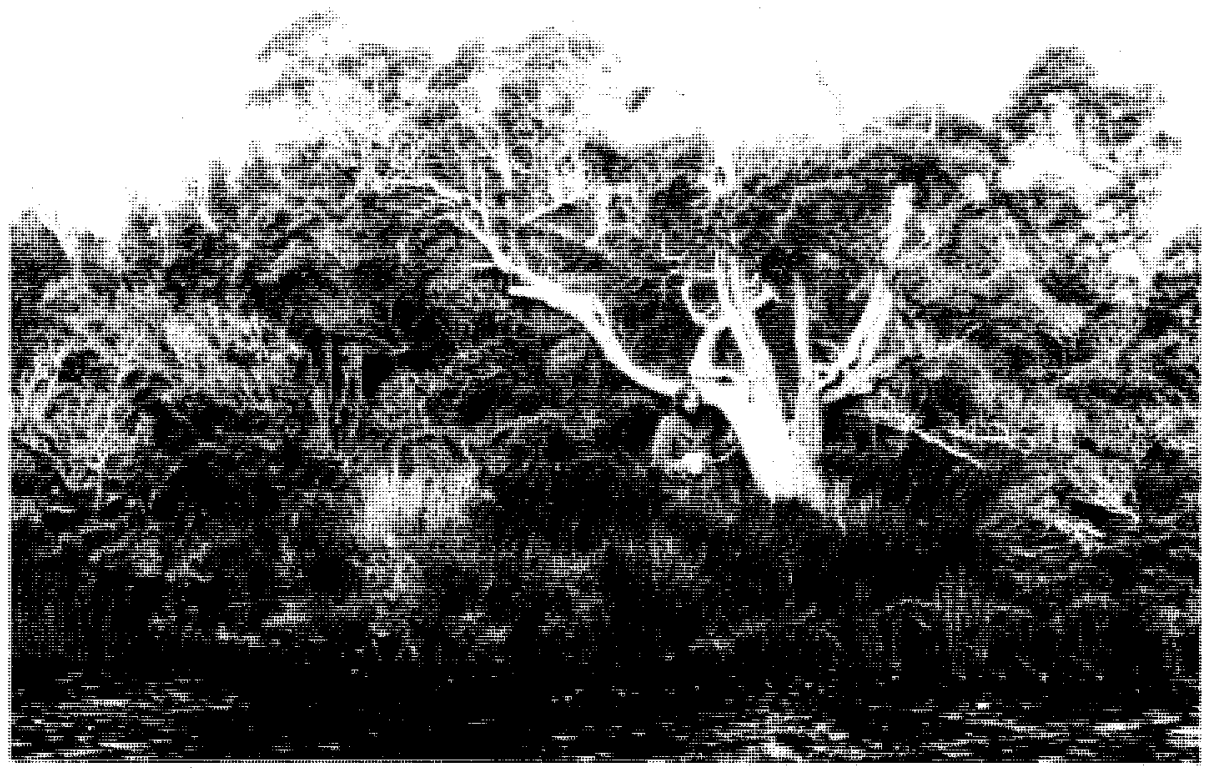

PLATE 1. - Typical vegetation of the larger islands showing zones. The figure leaning on an individual of Athrotaxis cupressoides is $2 \mathrm{~m}$ tall. 


\section{J.B. Kirkpatrick}

sheltered from the fire-associated westerly and northwesterly winds by the water-body. The major evidence for lack of at least recent fire on the islands is the widespread presence of the gymnosperms (Athrotaxis cupressoides, A. selaginoides, Diselma archeri and Phyllacladus aspleniifolius) and the winter deciduous angiosperm Nothofagus gunni $i$. These species are all extremely fire sensitive and seem capable of only slow peripheral recolonization of burnt areas. They are also very slow growers, yet mature specimens are the rule rather than the exception on the islands. Some recent deaths of some of these species have occurred, resulting in extinction on one or two of the smaller islands, but the deaths were almost certainly the product of other causes than fire.

The conversion of the lakeshore vegetation from temperate rainforest to scrub, sedgeland and moorland would have taken place at least several decades ago as the skeletons of the Athrotaxis species are reasonably durable, and are absent throughout most of the area. The conversion may have resulted from aboriginal firing, but probably resulted from firing by prospectors in the nineteenth century, as the aboriginals appear to have rarely frequented the high rainfall montane areas, most of their archeological remains being concentrated along the coast and in the dry east of Tasmania (Bryden and Ellis 1965). Before the conversion took place plant extinctions on the lake islands would have been compensated by immigration from the similar shore vegetation. Since the conversion the incoming disseminules carried by the prevailing westerlies have been those of moor and sedgeland species. Thus, it could be expected that the smallest islands, which should experience the highest extinction rates owing to low populations of individual species (McArthur and Wilson 1967), would have the highest proportions of moorland and sedgeland species in their floras. The bottom graph of figure 2 shows a tendency towards this relationship, with island 5 being the main exception. However, this island is situated to the leeward of one of the largest islands (fig. 1), and thus would receive most of its disseminules from this source.

\section{REFERENCES}

Bryden, W. and Ellis, W.F., 1965: Aboriginal population, in J.L. Davies (Ed.) ATLAS OF TASMANIA, 38. Mercury Press, Hobart.

Curtis, W.M., 1956: THE STUDENT'S FLORA OF TASMANIA, PART I. Government Printer, Ta smania. Tasmania.

1963: THE STUDENT'S FLORA OF TASMANIA, PART II. Government Printer, 1967: THE STUDENT'S FLORA OF TASMANIA, PART III. Government Printer, Tasmania.

Jackson, W.D., 1968: Fire, air, water and earth - an elemental ecology of Tasmania. Proc. ecol. Soc. Aust., 3, 9-16.

MacArthur, R.H., and Wilson, E.0., 1967: THE THEORY OF ISLAND BIOGEOGRAPHY. Princeton University Press, Princeton.

Willis, J.H., 1970: A HANDBOOK TO PLANTS IN VICTORIA, VOLUME I. Melbourne University Press, Carlton. 


\section{APPEND IX}

Species collected from the Lake Dora Islands, Tasmania $e=$ Tasmanian endemic; $s=$ shrub or tree species; $m=$ usually confined to $s c r u b$, moorland or sedgeland.

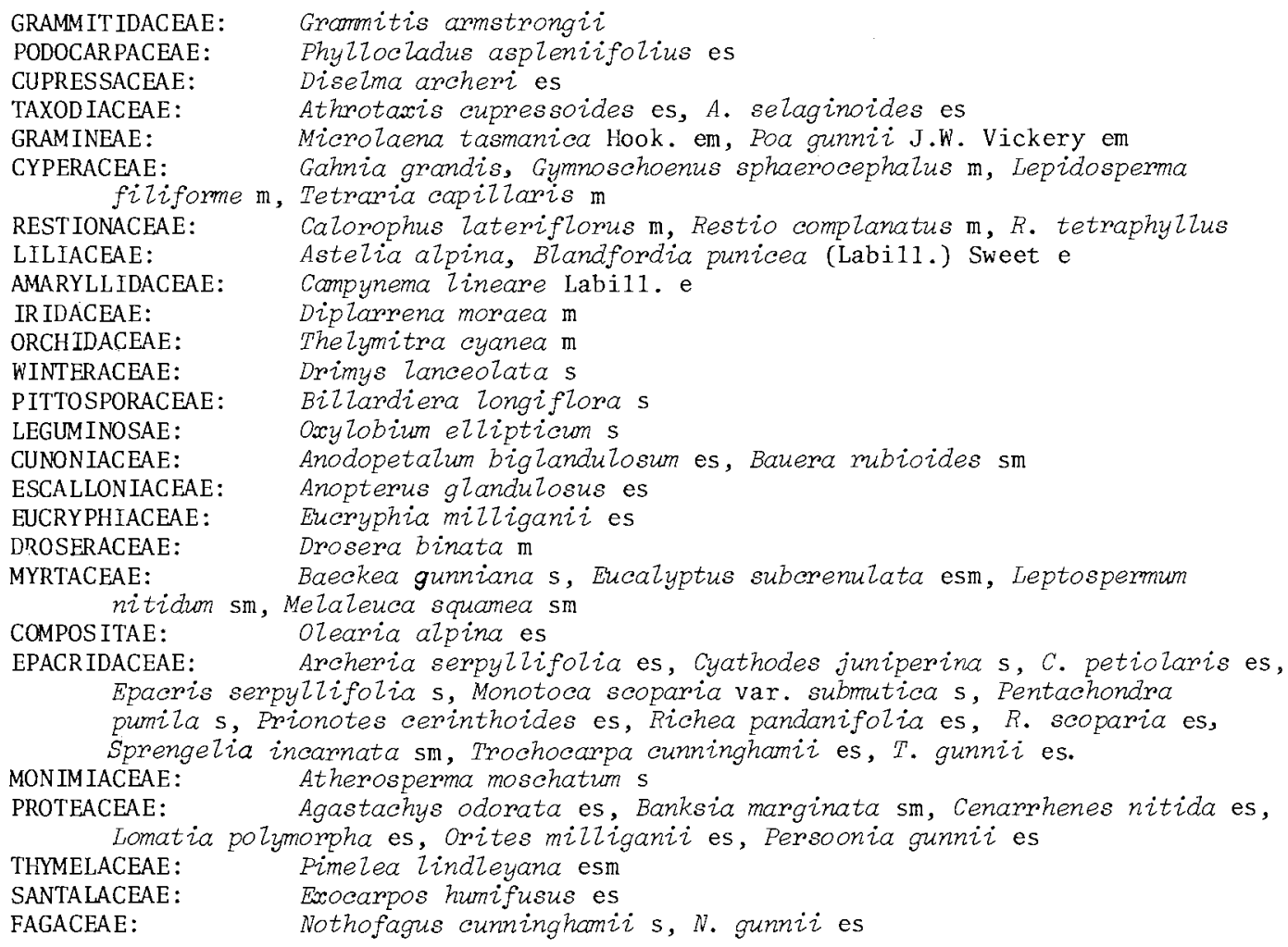

